Gut, 1982, 23, 169-171

Epidemiology

\title{
Family incidence of carcinoma of the colon and rectum in north-east Scotland
}

\author{
J L DUNCAN AND J KYLE \\ From the Department of Surgery, Royal Infirmary, Foresterhill, Aberdeen, Scotland
}

SUMMARY Family histories were obtained from 50 patients with adenocarcinoma of the colon or rectum in north-east Scotland. A comparable control group was similarly interviewed and in each group the case notes of the first degree relatives were studied where possible. Eight $(16 \%)$ of the patients with cancer of the colon or rectum had a close relative with intestinal cancer compared with one $(2 \%)$ of the control group. The patients with a positive family history of cancer of the large intestine did not have a higher proportion with adenomatous polyps nor were they younger than those patients with no such family history.

The aetiology of carcinoma of the colon and rectum is not fully understood. Dietary factors have been suggested but the effect of heredity has not been investigated in detail. There is evidence, however, which suggests that there are genetic factors influencing the incidence of the disease.

This study was undertaken to determine whether or not there is an increased incidence of cancer of the large intestine in the first degree relatives of patients with the disease. There is particular interest in the epidemiology of this condition in Aberdeen because of its very high incidence in north-east Scotland.

\section{Methods}

Fifty consecutive patients admitted to the Aberdeen group of hospitals were entered into the study. They all had histologically proven adenocarcinoma of the colon or rectum (large intestinal cancer), were well enough to give a clear family history, and did not suffer from any disease known to predispose to intestinal cancer. Each patient was interviewed and a detailed family history obtained. The relatives inquired about were parents, siblings, and childrenthat is, the first degree relatives. Direct questions were asked about the medical history of each of these individuals and specifically whether any had had bowel malignancy. If there was doubt about any of the

-Address for reprints: Mr J Kyle, Gastroenterology Research Unit, Ward 32. Royal Infirmary, Foresterhill, Aberdeen AB9 2ZB, Scotland.

Received for publication 1 July 198 I information given by the patient, one of these first degree relatives was also interviewed.

The hospital case records of any relative who had been seen by the hospital services were then studied, looking for large intestinal cancer. Case records in north-east Scotland are centralised in Aberdeen. If, from the history, any relative not living in the area at present was suspected of suffering from any bowel disease, copies of the relevant clinical notes were sought from the hospitals concerned. Only proven examples of adenocarcinoma were accepted.

Age- and sex-matched control patients were selected at random. These patients had been admitted to hospital for the treatment of various non-malignant conditions such as fractures, hernias, and appendicitis. The process of investigation in the control group was identical with that used in the intestinal cancer group. Each patient was told that he or she was a control in a study investigating the familial incidence of cancer of the large intestine. The two groups were interviewed concurrently.

\section{Results}

One of the cancer patients had two primary tumours, one in the sigmoid colon and the other at the hepatic flexure. There were, therefore, 51 tumours in the 50 patients and the sites of these lesions are given in Table 1. Place of birth and of present residence, whether urban or rural, were equally represented in the cancer and in the control groups.

The total number of relatives concerned was 
Table 1 Sites of tumours in 50 patients with cancer of large intestine

\begin{tabular}{lc}
\hline Sites of iumours & (No.) \\
\hline Caecum & 12 \\
Hepatic flexure & 1 \\
Transverse colon & 3 \\
Splenic flexure & 4 \\
Descending colon & 0 \\
Sigmoid colon & 18 \\
Rectosigmoid colon & 6 \\
Rectum & 7 \\
Total & 51 \\
\hline
\end{tabular}

similar, there being 349 relatives in the cancer group and 386 in the control group. There were also comparable numbers in each generation of relatives still alive.

The hospital case records of about $30 \%$ of the relatives in each group were reviewed. A similar percentage of relatives did not now live in the area. The remaining $40 \%$ were made up of those healthy relatives who had never had occasion to be seen by any of the hospital services or who had died in the early years of life (before the age of 12 years).

Eight patients out of the 50 in the cancer group had a first degree relative with cancer of the large intestine. The exact relationships of the patients and their relatives are given in Table 2 . Only one of the 50 control patients had a first degree relative with intestinal cancer. Analysis of this difference by Fisher's exact test gives a value of $\mathrm{P}>0.05$ (two tails).

Adenomatous polyps found in the operative specimen submitted for pathological examination or noted to be present at the time of diagnosis were recorded for the 50 cancer patients. Among the eight patients with an affected first degree relative, $25 \%$ had polyps, while for the 42 patients whose families were free from large intestinal cancer the incidence of polyps was $24 \%$.

\section{Discussion}

The north-eastern part of Scotland is an area known to have a.high incidence of cancer of the large intestine. ${ }^{1}$ It is thought to be part of a band of high incidence crossing north-east and central Scotland. ${ }^{2}$ In the present study in this high risk area, $16 \%$ of patients presenting with cancer of the large intestine already had a first degree relative suffering from the disease. As only proven examples in families were accepted, this percentage may be an underestimate, even at the time of study. More relatives may develop cancer in future years.

A number of workers have tried to estimate to what extent genetic factors influence the incidence of cancer of the large intestine. The first of these studies was from Utah ${ }^{3}$ and showed a higher number of deaths from intestinal cancer in the first degree relatives of patients dying from the disease than was found in control subjects. Macklin, ${ }^{4}$ working in Ohio, showed a similar increase in death rates from the condition in both first and second degree relatives compared with controls. In both of these retrospective studies no account was taken of the number of patients who, having contracted the disease, did not then die from it, as the data were gained solely from death certificates, which are not always accurate. Neither study can claim to have successfully excluded patients with diseases such as polyposis coli because case records were not examined.

Mortality figures were examined more recently by Lovett. ${ }^{5}$ Looking prospectively at a London referral hospital population of patients with cancer of the colon and rectum, she obtained information about first degree relatives. There was a threefold increase in the death rate from intestinal cancer among the relatives over that which would be expected in a comparable group of the general population. She also suggested that the presence of adenomas, multiple

Table 2 Relationships of patients to their affected relatives in both colon and rectum cancer and control groups

\begin{tabular}{|c|c|c|c|c|c|c|}
\hline & \multicolumn{2}{|c|}{ Relationship } & \multicolumn{2}{|l|}{ Site of tumour } & \multicolumn{2}{|c|}{ Age al diagnosis (yr) } \\
\hline & Patient & Relative & Patient & Relative & Patient & Relative \\
\hline \multicolumn{7}{|c|}{ Colon cancer group } \\
\hline 1 & Female & Sister & Sigmoid & Sigmoid & 73 & 53 \\
\hline 2 & Male & Mother & Splenic flexure & Rectum & so & 71 \\
\hline 3 & Male & Brother & Rectum & Rectum & 70 & 75 \\
\hline 4 & Male & Mother & Caecum & Rectum & 43 & 63 \\
\hline 5 & Male & Mother & Sigmoid & Rectum & 58 & 58 \\
\hline 7 & Female & Sister & Transverse & Rectum & 88 & 54 \\
\hline 8 & Male & Son & Sigmoid & Descending and & & \\
\hline & & & & hepatic flexure & 73 & 30 \\
\hline Mean & & & & & 64 & 57 \\
\hline \multicolumn{7}{|l|}{ Control group } \\
\hline 1 & Female & Father & None & Rectum & 72 & 85 \\
\hline
\end{tabular}


carcinomas, or an early age of onset, may be associated with a likelihood that the individual will have a family history of intestinal cancer. Anderson ${ }^{6}$ also supports the view that in families with more than one affected member the age of the patients is younger than that found in intestinal cancer patients with no positive family history. Lynch and his colleagues? considered that there was likely to be a preponderance of right-sided lesions in 'cancer families'.

The present investigation does not confirm any of these suggestions. The mean age of the Scottish patients with a family history was similar to that for the whole group (Table 2). The larger series ${ }^{1}$ from the same geographical area also contains a $2 \%$ proportion of patients below 40 years of age, so that it is unlikely that the patients studied were unusually elderly. In the patients with adenomatous polyps two out of $12(16 \%)$ had a family history of cancer of the large intestine, exactly the same percentage as in the whole group together. Only two of the eight tumours from the patients with a family history $(25 \%)$ were right sided This figure is less than the $35 \%$ of tumours which were found to be right sided in $1975 .{ }^{1}$ There is, therefore, no right-sided predominance in the cancer group. The single patient with two primary tumours did not have a family history, although it is interesting to note that one of the relatives did have two primary tumours at a very young age. In five out of eight affected relatives, the carcinoma was in the rectum. The numbers are too small to come to definite conclusions but it would certainly be beneficial to subject the site of the cancer to further study.

The investigation most closely comparable with the present study is that of Lynch and his co-workers in Omaha. ${ }^{8}$ Among 50 patients in Nebraska they found 15 first degree relatives who had also suffered from the disease. These 15 relatives, however, were distributed between only eight families (16\%). This figure of $16 \%$ is exactly the same as our own, although we did not find any family with more than two relatives affected by the disease. The Omaha group has subsequently discovered a number of so called 'cancer families' and certain families in their study of cancer of the large intestine might well be considered to fit into this category. It is certainly possible, however, that if the
Scottish families were followed for a long period more individuals would be found to develop the condition.

There would seem to be little doubt that this increased familial incidence is not a chance finding. Whether it is caused by purely genetic factors is not clear. It is more likely that cancer of the colon and rectum has a multifactorial aetiology, one factor being a genetic predisposition.

Approximately $50 \%$ of patients presenting with cancer of the colon and rectum are incurable by present-day methods of treatment at the time of diagnosis. ${ }^{10}$ If this high percentage is to be reduced cases must be diagnosed earlier. Screening for the disease has been carried out ${ }^{1112}$ but the problem is how to recognise the high risk groups. The present study has identified a group with a much increased incidence of cancer of the large intestine and the screening of families with an affected member warrants consideration.

\section{References}

${ }^{1}$ Kyle J, Petrie MX. Carcinoma of the colon and rectum in north-east Scotland. J R Coll Surg Edin 1979; 24:22-7.

${ }^{2}$ Berg JW. Bowel cancer in Scotland. Lancet 1972; 2:486.

${ }^{3}$ Woolf CM. A genetic study of carcinoma of the large intestine. Am J Human Genet 1958; 10:42-7.

${ }^{4}$ Macklin MT. Inheritance of cancer of the stomach and large intestine in man. J Natl Cancer Inst 1960; 24:551-71.

${ }^{5}$ Lovett E. Family studies in cancer of the colon and rectum. Br J Surg 1976; 63:13-8.

${ }^{6}$ Anderson DE. The risk in families of patients with colon cancer. Prog Cancer Res Ther 1980; 13:109-15.

${ }^{7}$ Lynch PM, Lynch HT, Harris RE. Hereditary proximal colonic cancer. Dis Colon Rectum 1977; 20:661-8.

${ }^{8}$ Lynch HT, Guirgis H, Swartz M, Lynch J, Krush AJ, Kaplan AR. Genetics and colon cancer. Arch Surg 1973; 106:669-675.

${ }^{9}$ Lynch HT, Harris RE, Organ CH et al. The cancer family syndrome. Ann Surg 1977; 185:435-40.

${ }^{10}$ Clarke DN, Jones PF, Needham CD. Outcome in colorectal carcinoma: seven-year study of a population. $\mathrm{Br} \mathrm{Med}$ $J$ 1980; 1:431-5.

"Hardcastle JD, Balfour TW, Amar SS. Screening for symptomless colorectal cancer by testing for occult blood in general practice. Lancet 1980; 1:791-3.

'LWinamer SJ. Screening for colorectal cancer: an overview. Cancer 1980; 45:1093-8. 